\title{
Rainfall Data as a Case for Investigation into Climate Change in Ghana
}

\author{
Frank S. Arku \\ Faculty of Development Studies, Presbyterian University College, Ghana \\ Akuapem Campus \\ E-mail: fsarku@gmail.com
}

\begin{abstract}
Climate change has become a catch phrase in all disciplines, and research has shown that global temperature is increasing as a result of climate change. However, much has not been done on whether only analysis of rainfall data, without linking it to its impact on a particular case such as food production evidences climate change. This study therefore analysed merely rainfall data to determine whether it is an indication of climate change. Rainfall data was collected from 8 synoptic meteorological stations in Ghana for a 40-year period (19662005). The results have shown that average rainy days and average total rainfall for selected months for selected stations have varied which according to the working definition cannot be referred to as climate change. By using the normalised rainfall departure approach, rainfalls have also varied from year to another, but cannot also be referred to as climate change.

The Sahelian drought might have extended to the northern Ghana because there were continuous negative rainfall departures (meteorological drought) in stations in the northern Ghana from 1966 to 1975 . Based on the findings of this research, in order to conclude that climate in Ghana has changed using rainfall as a case, timeline research needs to be conducted which should focus on the impacts of rainfall on, for example, crop production and/or river discharge.
\end{abstract}

Keywords: climate change, Ghana, rainfall variability, drought, Sahelian.

\section{Introduction}

To effectually argue on climate change, it is suitable to situate it within the existing content, globally accepted scientific literature. Thus, the paper started by 
providing the definition for the term climate change. The Fourth Assessment Report [1] refers to climate change as any change in climate over time, whether due to natural variability or as a result of human activity. This definition is different from that of United Nations Framework Convention on Climate Change which refers to a change of climate as a result of direct or indirect human activity that alters the composition of the global atmosphere and that in addition to natural climate variability observed over a comparable time periods [1]. [2] also refers to climate change as a substantial and long-lasting change in the weather patterns over a long period of time. Though the duration of the changes in climate may vary, variations which last for a few years should not be immediately be concluded as evidence of climate change.

Critical analysis of the definitions of climate change has shown that although climate change is a change in 'climate', none of the definitions indicated the exact number of years for which a change should occur to be referred to as climate change. But Ngaira [2] which definition is the working definition of this study maintain that the change should be a long period of time, and this paper considers that the change should be at least ten years. A popular misconception of climate change is that it is directly synonymous with global warming. Climate change includes, but is not limited to global warming.

Causes of climate change may be natural, anthropogenic, or both $[3,1]$. The anthropogenic cause results in increase in atmospheric greenhouse gases, especially carbon dioxide $\left(\mathrm{CO}_{2}\right)$. The increase in greenhouse gases in the atmosphere may have several effects on the climate. It is therefore the manifestation of those effects that is evidence of the reality. Some evidences include increase in surface temperature, melting of glaciers (and subsequent rise in sea level), and change in precipitation $[1,4]$. Research has largely documented that the global temperature has increased as a result of climate change, however, much has not be done on whether analysis of only rainfall data, without connecting it to its effect on a particular case, evidences climate change. This study therefore analysed only rainfall data to determine whether it evidences a change in climate. Also, the total amount of rainfall and its distribution play important roles in agricultural output, especially in arid and semi-arid regions [5, $6,7)$ so it is therefore important to document the pattern of rainfall in rainfed agricultural areas.

When analysing climate data, it is important to be able to distinguish between climate change and climate variability. While, climate change refers to sustained change in climate over long periods - the working definition-, and in this case at least 10 years, climate variability is the climatic fluctuations that last for very short periods, most often on yearly basis [8]. Thus, constant up-down pattern is indication of rainfall variability, a phenomenon which is normal. Because the mechanisms that drive rainfall is quite complex, it is quite normal for annual precipitations to alternate between highs and lows. These high and low values have to be analysed over long periods (decades or even centuries) before one can confidently determine whether climate has changed or not. 


\section{The Study Region and Methods}

Ghana which is the focus of this study can be divided into two climatic regions: the north, which is arid, and the south which is semi-arid and surrounded by the Gulf of Guinea. Because of the two distinct climatic zones, fluctuations in rainfall may not always be identical for both regions.

Data for monthly total rainfall for eight synoptic stations (Figure 1) were collected from Ghana Meteorological Agency for a 40-year period, which is from 1966 to 2005. Data on the number of rainy days for selected stations and selected months were collected for a 20-year period (1981 to 2000). Trace amounts of rainfall were considered to be zero when performing calculations with these figures.

Line graphs were constructed to depict various form of information, including normalized rainfall departure, number of rainy days, and trend of average monthly rainfall.

Normalized rainfall departure is a way of measuring the deviation of each of the yearly rainfall values from the mean over the 40-year period. It is in some ways related to the standard deviation. The departures for each year was calculated using the equation 1 below,

$$
\mathrm{x}_{\mathrm{ij}}=\left(\mathrm{r}_{\mathrm{ij}}-\overline{\mathrm{r}}_{\mathrm{i}}\right) / \sigma_{\mathrm{i}}
$$

Where:

- $\quad \mathrm{x}_{\mathrm{ij}}=$ annual rainfall departure

- $\mathrm{r}_{\mathrm{ij}}=$ the annual total for station $i$, and year $j$

- $\quad \overline{\mathrm{r}}_{\mathrm{i}}=$ the annual mean rainfall at station $i$ averaged over the entire length of record -40 years

- $\sigma_{\mathrm{i}}=$ the standard deviation of the annual totals. 


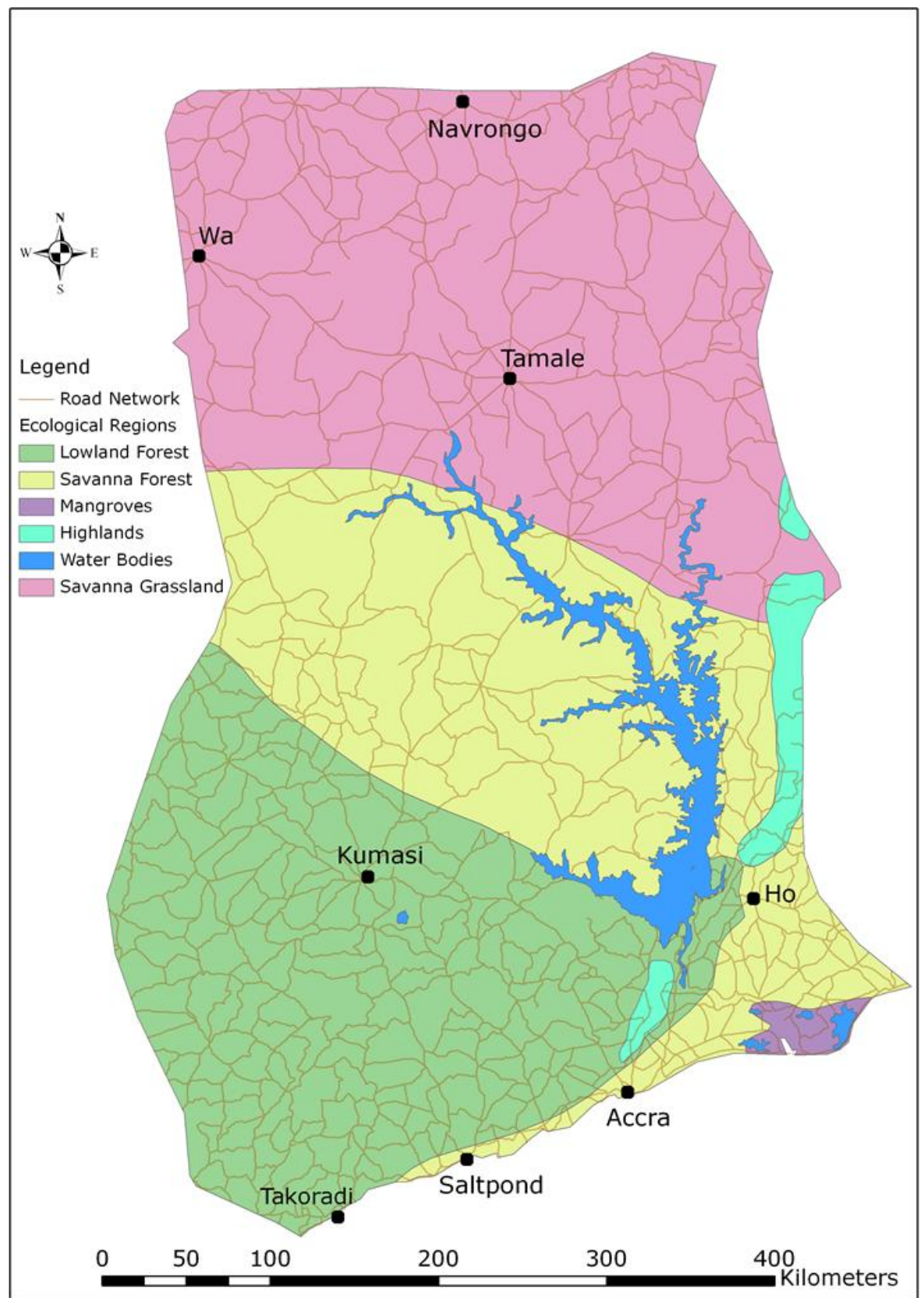

Fig. 1: The study station

The 1981-2005 data was used to show the pattern of average monthly rainfall. The data for 1966 to 1980 was not included because the available data was on yearly total rainfall, but not also on the total monthly rainfall.

Graphs on rainy days were drawn to show the number of days it rained during selected months. The purpose was to determine the frequency at which rain fell within the months under consideration. 


\section{Results and Discussion}

\section{1 Average Monthly Rainfall Pattern}

Figures 2-5 show average monthly rainfall pattern from 1966 to 2005 for four of the eight stations. While the highest average monthly rainfall at Wa was in the month of August for the period under study (Figure 2), it was in September at Tamale (Figure 3). Generally, the rainfall increases gradually from the month of March and reaches its maximum in August (Figure 2) and September (Figure (3), and drops thereafter. This is the general pattern of rainfall in northern Ghana (Figure 1) and since the maximum rainfall occurs once in a year, the pattern can be referred to as a single rainfall maximum.

Figures 4 and 5 have double rainfall maxima which is typical of rainfall pattern in southern Ghana (Figure 1). The first average maximum was in June for both Takoradi and Kumasi, and the second maximum was in October and September, respectively (Figures 4 and 5), but the first maximum (June) is higher than the second one. These rainfall patterns account for the one farming season in northern Ghana and two in the southern Ghana (see Figure 1).

\subsection{Total Average Yearly Rainfall and Number of Rainy Days for Selected Months}

The least total average rainfall for the month of May at Wa and the least number of rainy days were in 1987 (figures 6 and 7, respectively); another least number of rainy days with the same rainfall amount as 1987 was in 1993. Also, just like 1998 when one of the minimum rains was recorded (Figure 6), one of the minimum rainy days was also recorded in the same year (Figure 7). Thus, generally the total average yearly rainfall in May at Wa has somehow direct relationship with the number of rainy days; the higher the total average rainfall, the higher the number of the rainy days and vice versa.

The relationship (direct relationship between the total average yearly rainfall and the number of the rainy days) that occurred in Wa in May is similar to the month of June at Wa, except for a few occasions (Figures 8 and 9). For example, although a minimum was recorded in 1996 in Figure 8, a maximum was recorded in the same year (Figure 9); the indirect relationship might be either as a result of a combination of the following factors or one of them - human error in the process of recording, faulty instrument used to record the rainfall, and the occurrence is natural. Another observation is that even though the rainfall has generally varied in May in the 25-year period at Wa (Figure 8), the variations from a year to another is higher from1996 to 2005 than from 1981 to1996. Also, on the average, the average yearly rainfalls from the latter period are higher than the former. 
The situations described for $\mathrm{Wa}$, that is almost a direct relationship between the average and the number of rainy days, are not very different from the data obtained on Takoradi (Figures 10, 11, 12 and 13).

Considering Figures 6 to 13, one cannot conclude that climate has changed using the two study stations as cases if climate change is sustained change in climate over a long period of time and in this case 10 years. Figures 6, 8, 10 and 12 have shown that the total average monthly rainfall have varied over the study area, with higher variations from 1996 to 2005 than from 1981 to 1995 (Figure 8) at Wa which according to the working definition cannot be referred to as climate change.

\subsection{Normalised Rainfall Departure}

The next step is to determine whether by the use of the normalized rainfall departure approach (see equation 1), there has been sustained change in rainfall pattern for at least 10 years, hence climate change. To determine climate change through normalised rainfall departure, data from selected stations which are Tamale, Wa, Takoradi and Accra (Figures 14-17) were used.

There was a continuous negative rainfall departure from 1966 to1974 in Tamale and in Wa from 1966 to 1975 (Figures 14 and 15); these stations are in the Northern Ghana (Figure 1). The negative departure is referred to as meteorological drought. As maintained by [9], there was a disastrous drought in West African Sahel from 1968-73 of which annual rainfall totals were below 50\% of the long-term average. The negative departures in the northern Ghana have coincided with part of the Sahelian drought which might have occurred as a result of a natural climate cycle $[10,11,12,13]$. Another school of thought was that the drought in the Sahel zone was caused by humans over-using natural resources in the region $[14,10]$. Up to 250,000 drought-related human fatalities occurred throughout the Sahel region between 1968 and 1973. The rain shortage has killed many of the crops and left people with very bad harvests $[15,16]$. In addition to the fact that the drought was meteorological one, it was agriculture drought because it also affected food production. The Sahelian drought might have extended to the northern Ghana resulted in the continuous negative departure.

Apart from the continuous negative rainfall departure that occurred in the northern Ghana as discussed, Figures14-17 have shown that using the normalised rainfall departure approach, rains have varied from one year to another without any prolonged positive or negative departure. Thus, again the normalised rainfall departure for these stations cannot be used as enough evidence that climate has changed.

Generally the data analyzed have shown that there were occasions when the yearly total average monthly rainfalls were below the averages (Figures 6, 8, 10 and 12), which is meteorological drought, and sometimes they were above the average. These departures might or might not be issues as far as crop production is concerned. For example, a meteorological drought might not negatively affect crop production (agricultural drought) if the rains are enough for crop production 
and well distributed when they are needed by the crops. Also, positive departures might lead to flood destroying farms, might be too much for the crops hence destroying them, might be sufficient for crop production, and still even though it is a positive departure, it might not be sufficient for crop production.

Without even referring to crop production in terms of climate change, in order to establish the fact that climate has changed using rainfall as evidence, we need to have either continuous positive or negative change for maybe a decade which is not the case for this study. As a result one needs to further conduct empirical investigation to determine whether the positive and the negative departures, and the rainy days have affected crop production or not.

\section{Conclusion}

Climate change is a global problem and research has shown that climate is actually changing, especially increasing temperature. This research has however shown that although some selected average rainfall data for selected stations in Ghana have varied, the variations are not long enough to conclude that climate has changed. But it cannot also be concluded that based on this research climate has not changed using rainfall as a case. It is possible that climate has changed and the change might be more conspicuous if the research focuses on, for example, climate change and rainfed agriculture and/or flow of rivers, which calls for further research.

\section{References}

[1] Intergovernmental Panel on Climate Change (IPCC). Summary for policymakers. In Parry, M. L., Canziani, O. F., Palutikof, P. J., van der Linden, P. J. and Hanson, C. E. (Eds.), Climate change 2007: Impacts, adaptation and vulnerability. Contribution of working group II to the assessment report of the intergovernmental panel on climate change (2007) (pp.7-22). Cambridge: Cambridge University Press.

[2] Ngaira, J. K, Impact of climate change on agriculture in Africa by 2030. Scientific Research and Essays 2(7) (2007): 238-243.

[3] Odjugo, P. A. O. Regional evidence of climate change in Nigeria. Journal of Geography and Regional Planning 3(6) (2010): 142-150

[4] Aizebeokhai, A. P. Global warming and climate change: Realities, uncertainties and measures. International Journal of Physical Sciences 4(13) [2009]: 868-879.

[5] Sivakumar, M. V. K., Das, H. P. and Brunini, O. Impacts of present and future climate variability and change on agriculture and forestry in the arid and semi-arid Tropics. Climate Change 70 (2005): 31-72. 
[6] Daşci, M., Koç, A., Binali, Ç. Güllap, M. K., Cengiz, M. M. and Erkovan, H. I. Importance of annual and seasonal precipitation variations for the sustainable use of rangelands in semiarid regions with high altitude. African Journal of Agricultural Research 5(16) (2010): 2182- 2191.

[7] Tilahun, K. Analysis of rainfall climate and evapo-transpiration in arid and semi-arid regions of Ethiopia using data over the last half a century. Journal of Arid Environments 64 (3) (2006) 474-487.

[8] Burroughs, W. J. Climate Change: A Multidisciplinary Approach [2007] Cambridge: Cambridge University Press.

[9] Nicholson, S. E. The nature of rainfall fluctuations in subtropical West Africa. Monthly Weather Review 109 (1980): 2191-2208.

[10] Otterman, L. Baring high-albedo soils by overgrazing: A hypothesized desertification mechanism. Science 186 (1974): 531-553.

[11] Walker, J. and Rowntree, P. R. The effect of soil moisture on circulation and rainfall in a tropical model. Quarterly Journal of Royal Meteorology Society 103 (1977): 29-46.

[12] Schell, R. C. Biogenic ice nuclei: Part 1 marine sources. Journal of Atmospheric Science 33 (1976): 1554-1564.

[13] Hare, F. K. Climate and desertification, Desertification: Its causes and consequences, UN Conferences on Desertification [1977], Pergamon, 63120.

[14] Charney, J. G. Dynamics of deserts and drought in the Sahel. Journal of Royal Meteorology Society 101 (1975): 193-202.

[15] Aiguo, D., Lamb, P. J., Trenberth, K. E., Hulme. M., Jones, P. D. and Xie, P. The recent Sahel drought is real. International Journal of Climatology 24 (11) (2004): 1323-1331.

[16] Zeng, N. Drought in the Sahel. Science 302 (5647) (2003): 999-1000. 

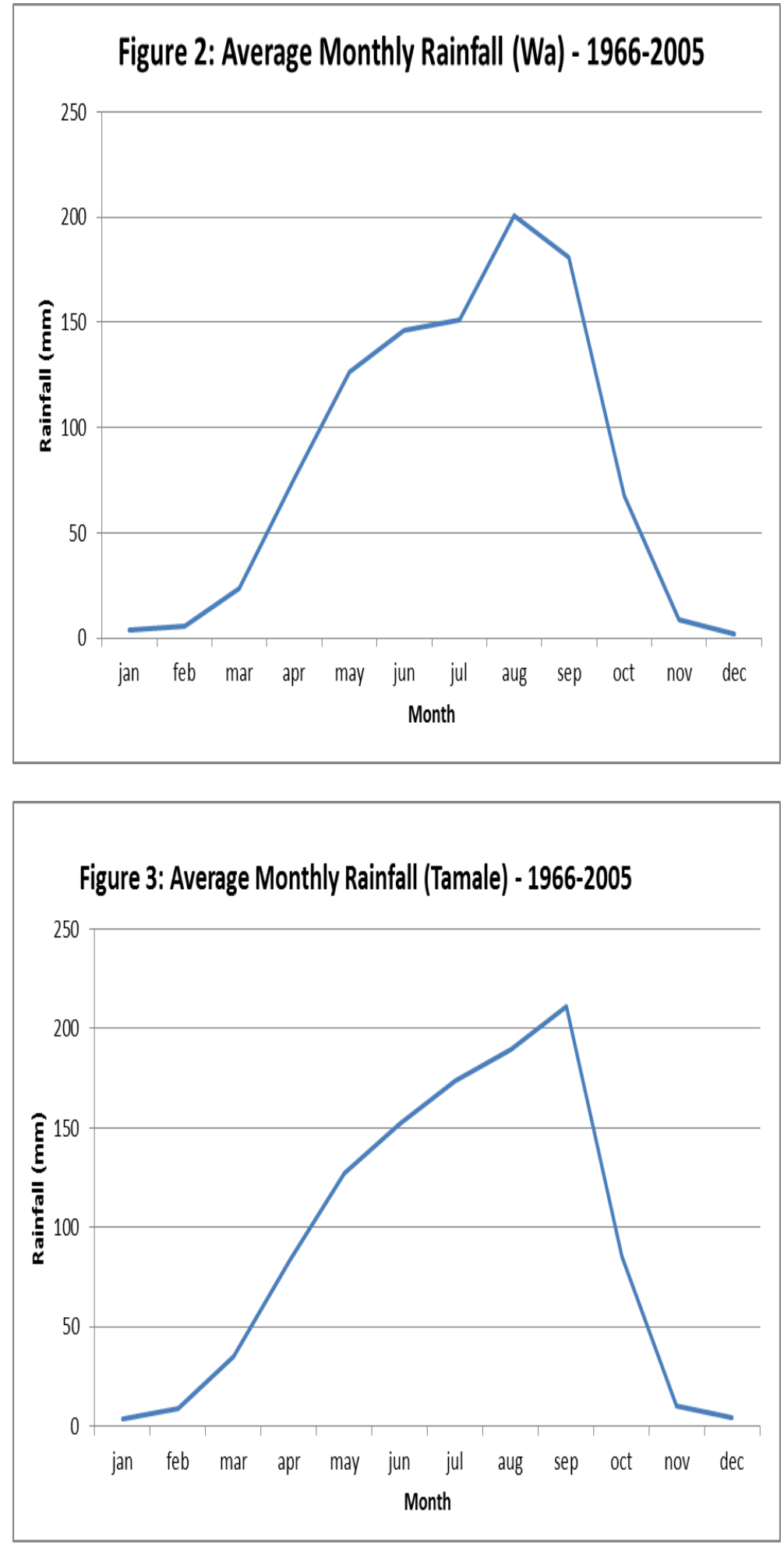

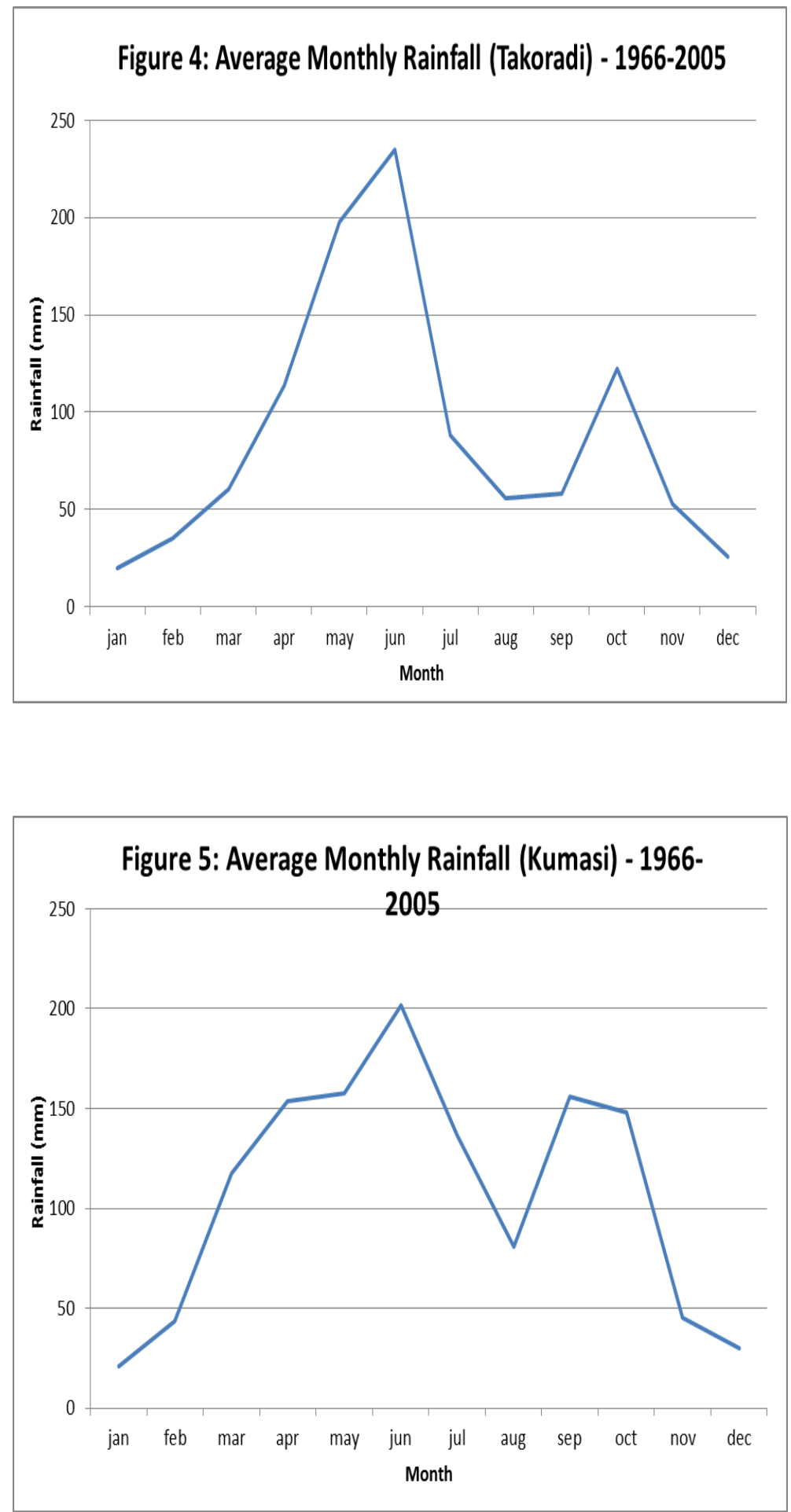

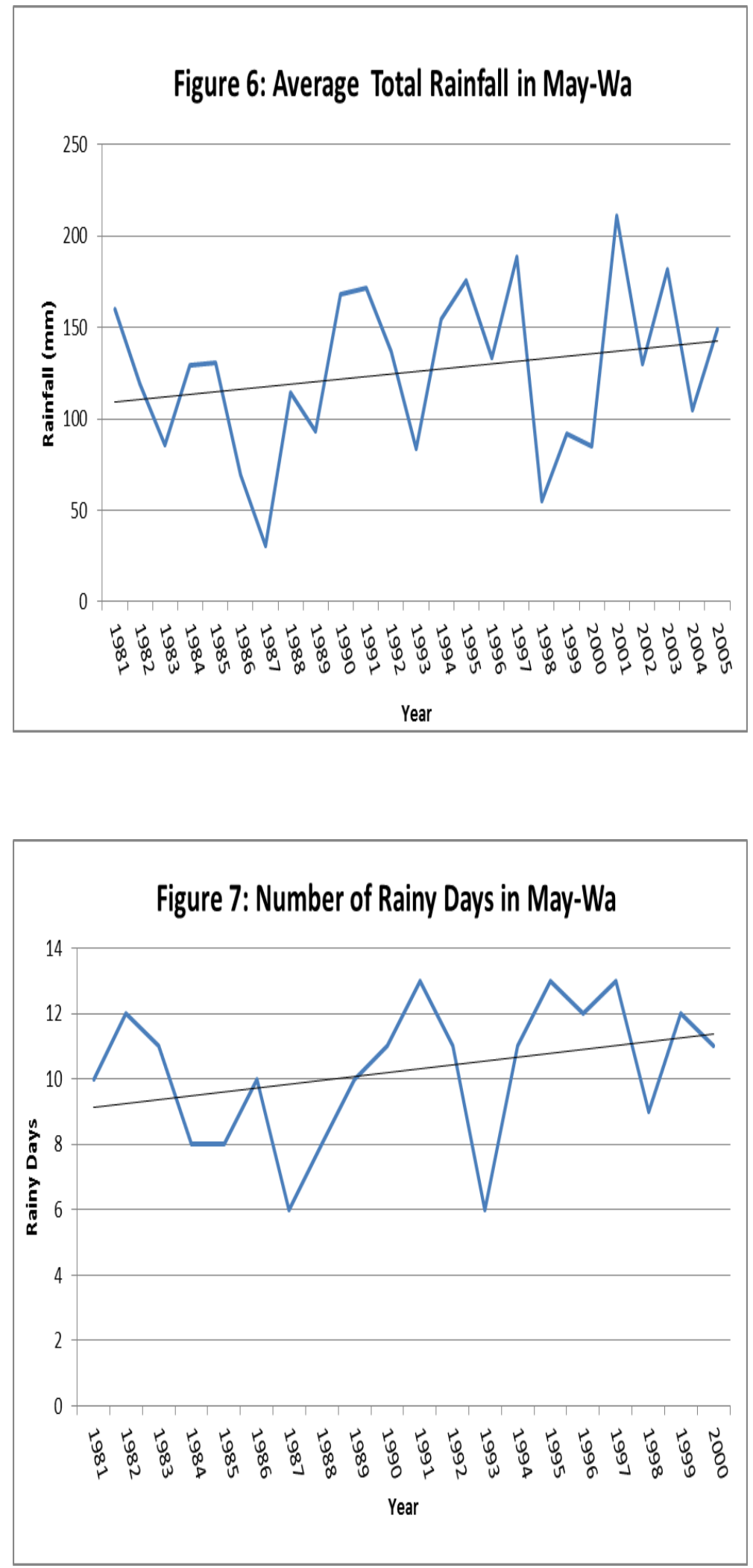

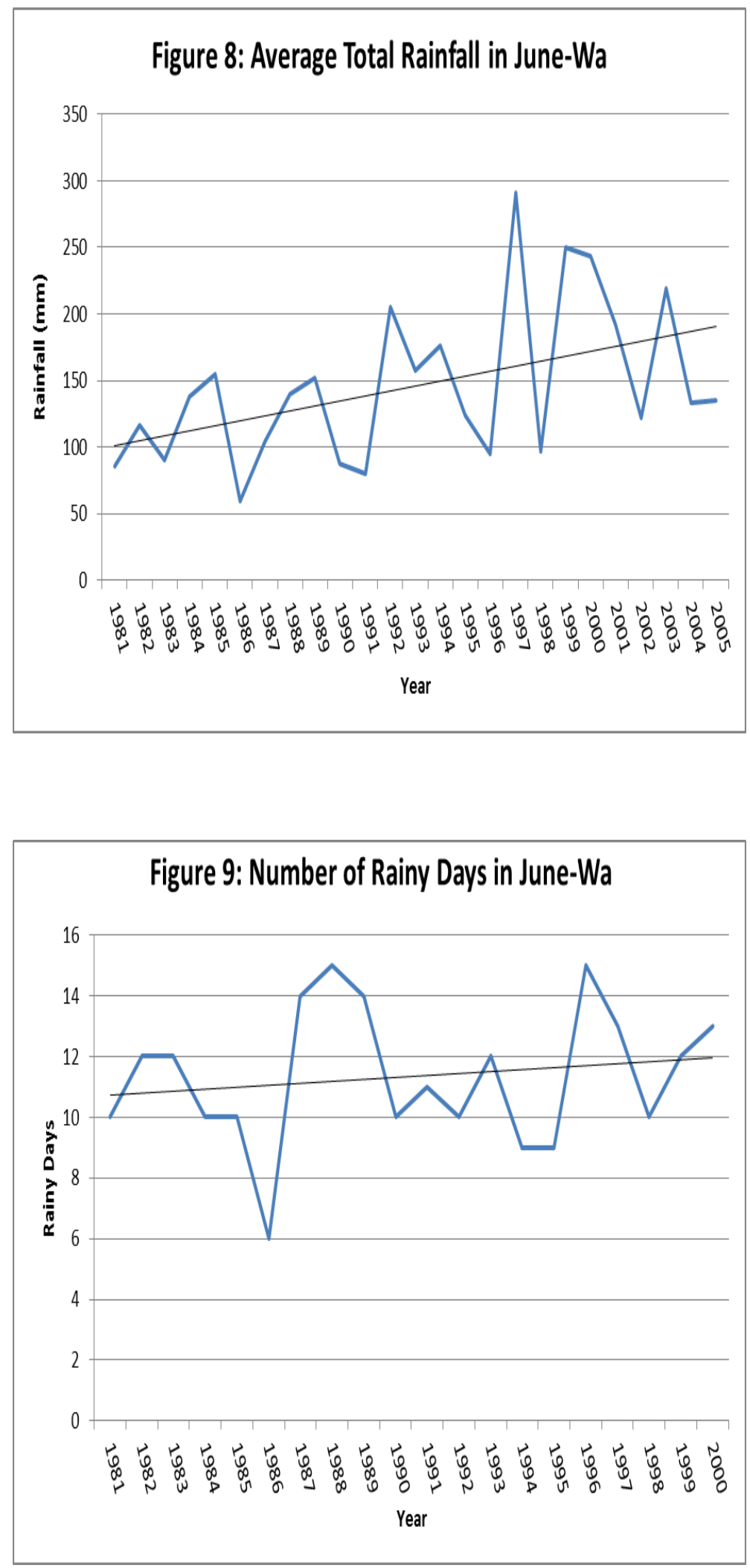

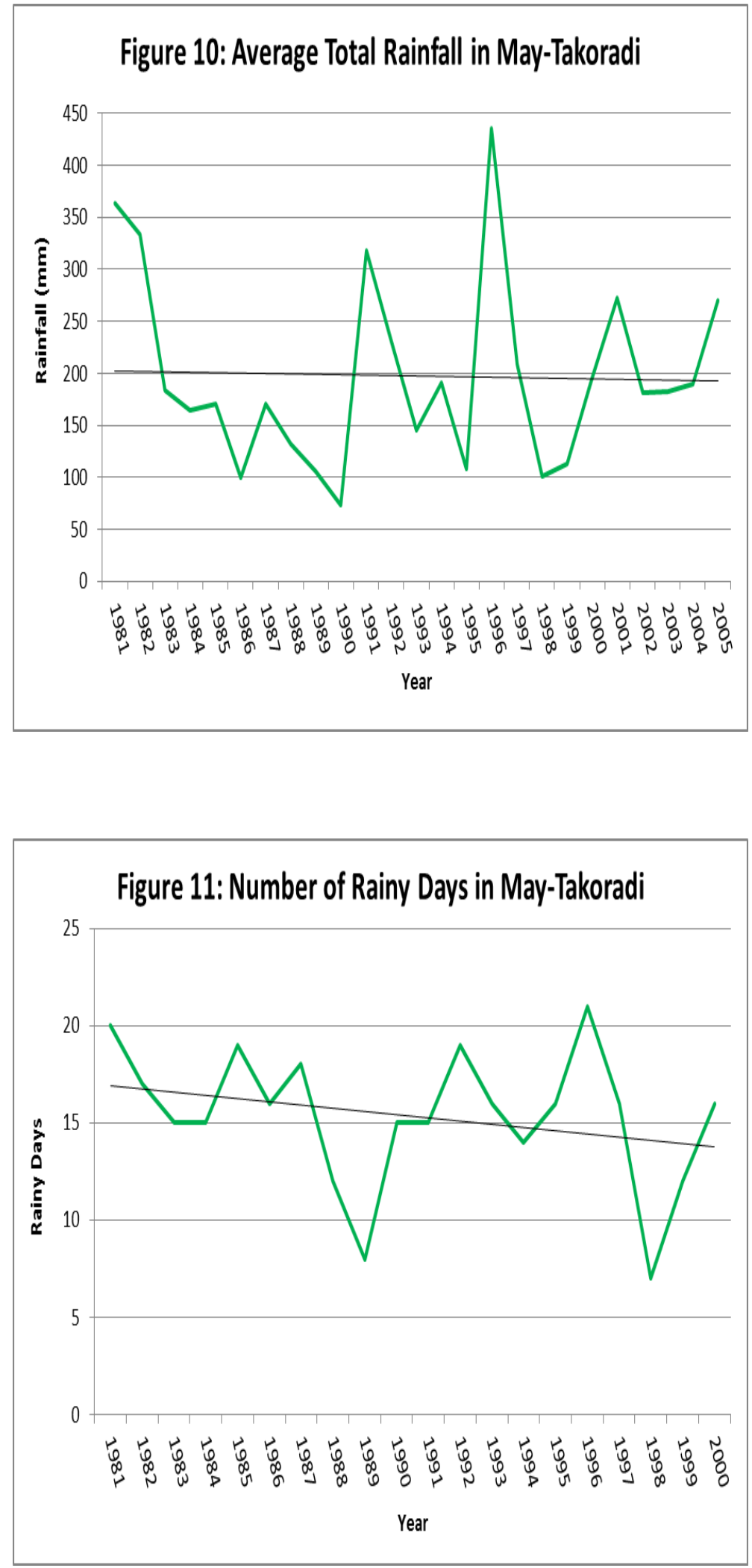

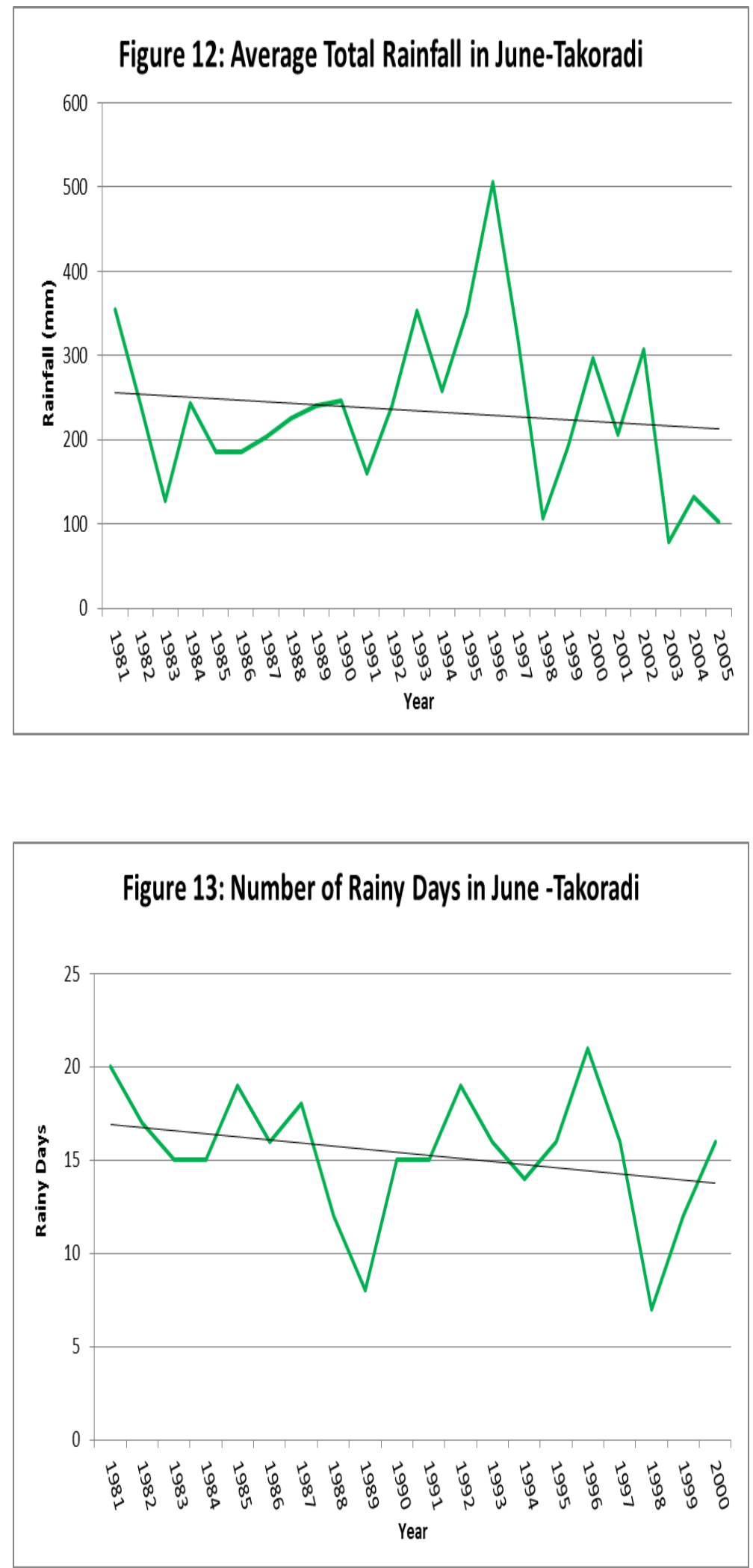

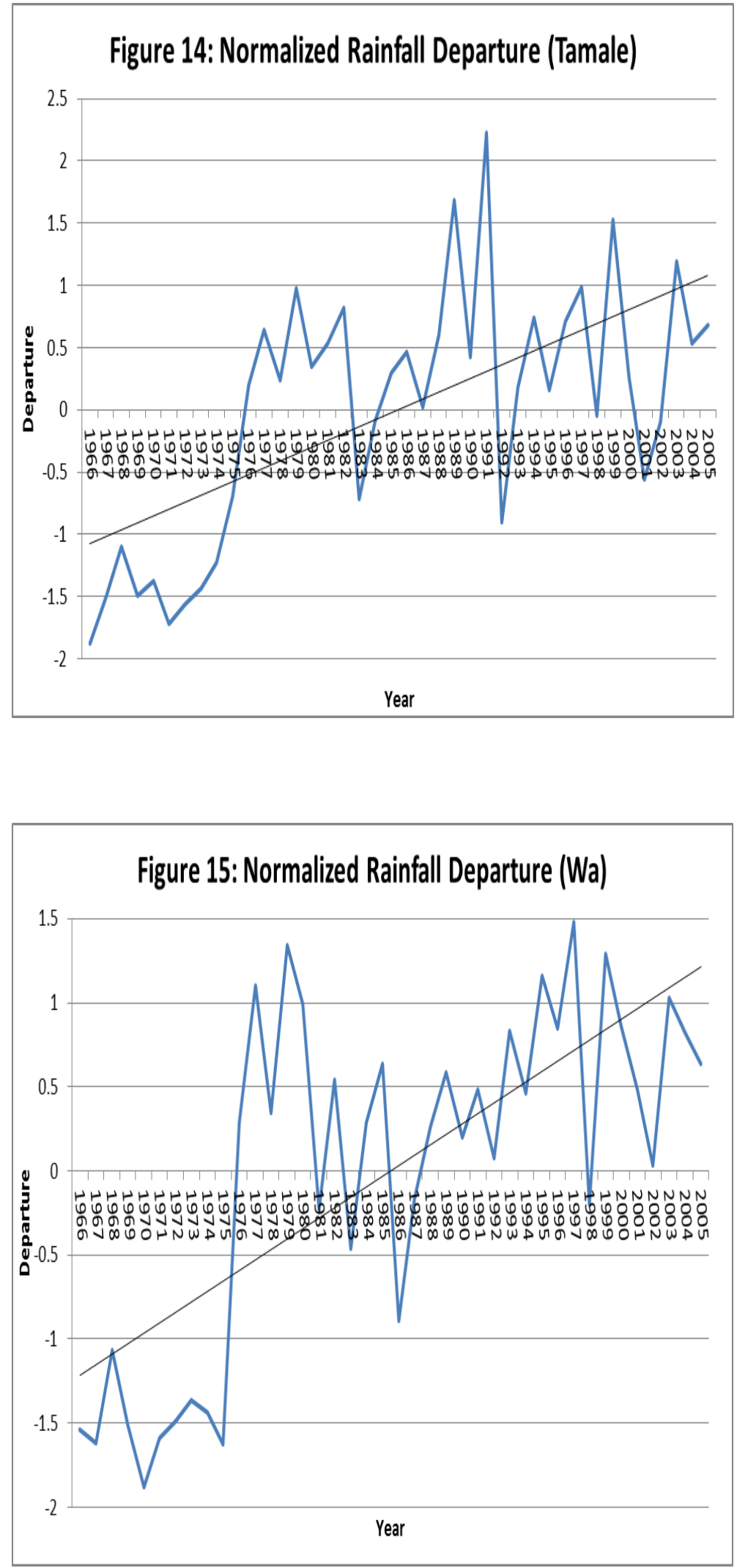

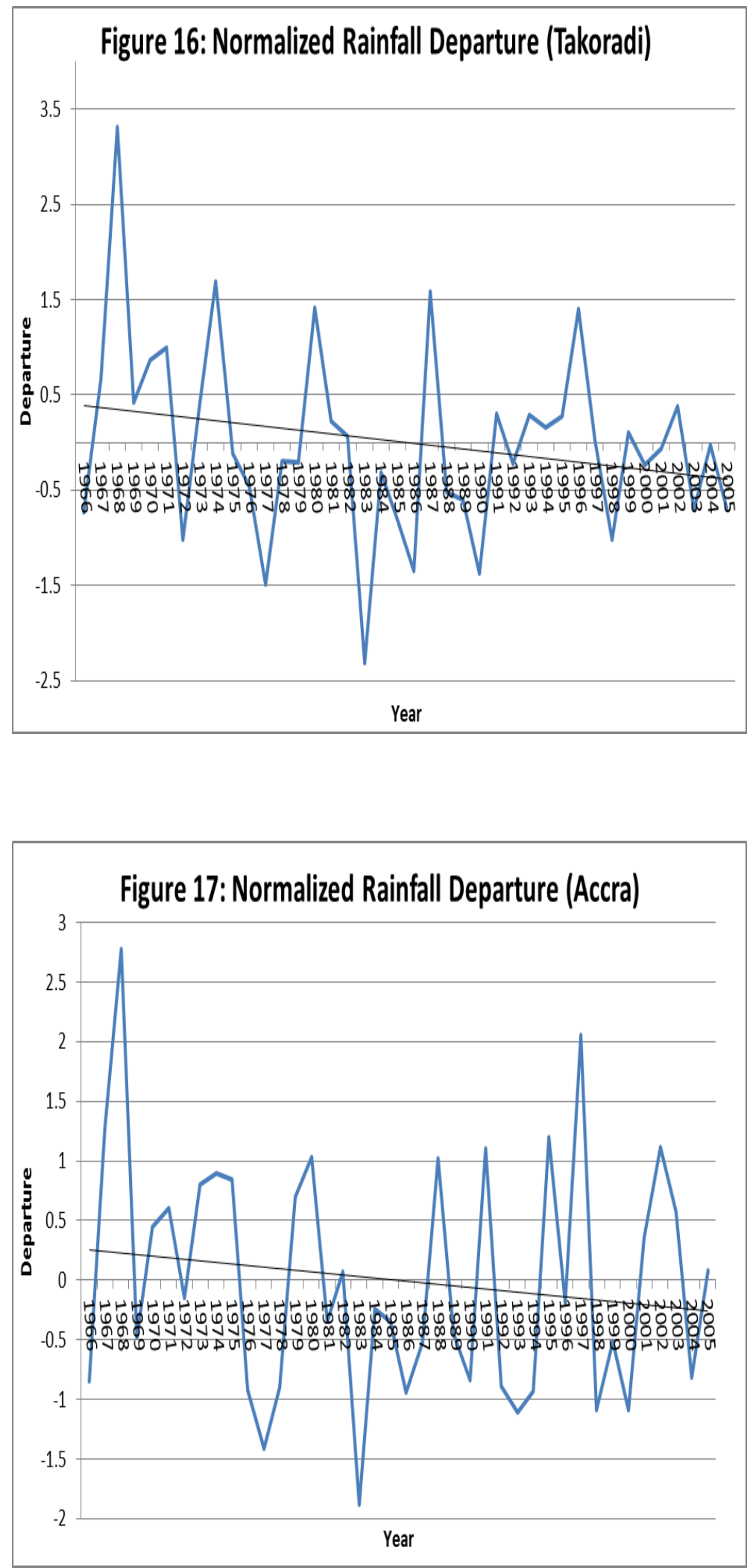